\title{
Depósitos tecnogênicos: uma nova perspectiva de leitura geográfica
}

\section{Technogenic deposits: a new geographical evaluation approach}

\section{Leda Correia Pedro Miyazaki}

Universidade Federal de Uberlândia lecpgeo@gmail.com

\begin{abstract}
RESUMO
O presente texto tem como objetivo apresentar uma discussão sobre a formação dos depósitos tecnogênicos, a partir da compreensão do processo de apropriação e ocupação do relevo, levando em consideração a categoria tempo histórico e os possíveis métodos de interpretação utilizados para realizar uma leitura geográfico-geomorfológica da paisagem tecnogênica. Para isso foi escolhido como área de estudo o Jardim Humberto Salvador, bairro localizado na cidade de Presidente Prudente-SP. Para realizar uma leitura geográfico-geomorfológica, utilizou-se como método de interpretação o materialismo histórico e dialético, para que fosse possível identificar a gênese dos diversos depósitos tecnogênicos, oriundos do processo de apropriação e de ocupação do relevo. Desta forma, foi possível compreender como os agentes de produção do espaço urbano contribuem para a formação dos depósitos tecnogênicos, além de enfocar algumas fases importantes que fazem parte da gênese dos depósitos, como, por exemplo, a implantação de um loteamento, a edificação do bairro (construção das residências) e o momento em que os moradores passam a residir no bairro. Todas essas fases deixam registros na paisagem, podendo ser desvendadas a partir da caracterização dos artefatos tecnogênicos encontrados nas camadas e da compreensão do histórico do bairro.
\end{abstract}

Palavras-chave: Depósitos tecnogênicos; Ocupação; Relevo; Tempo.

\section{ABSTRACT}

This work aims to present a discussion on the formation of technogenic deposits, from the understanding of the relief appropriation and occupation processes, taking into consideration the category historic-time and the possible methods of interpretation used to perform a geographic geomorphological reading of the technogenic landscape. The area of study is Jardim Humberto Salvador, a neighborhood located in the city of Presidente Prudente-SP. To perform a geographic geomorphological reading, we used the method of interpretation of the historical materialism and dialectic, so that it was possible to identify the genesis of the technogenic deposits, arising from the process of appropriation and occupation of relief. In this way, it was possible to understand how the agents of the production of urban space contribute to the formation of technogenic deposits, besides focusing on some important phases that are part of the genesis of such deposits, for example the deployment of allotment, the building of the neighborhood and the moment that residents come to reside in the place. All these phases leave a record in the technogenic landscape, that can be unraveled from the characterization of the technogenic artifacts found in layers and from the understanding of the historic of the neighborhood.

Keywords: Technogenic deposits; Occupation; Relief; Time.

\section{Introdução}

A Geografia é uma ciência que nos permite realizar uma série de análises das relações entre a sociedade e a natureza de forma articulada. No entanto, em trabalhos geográficos, algumas abordagens podem privilegiar as dinâmicas da sociedade sobre as dinâmicas da natureza, e em outras podem prevalecer as dinâmicas da natureza em detrimento das dinâmicas da sociedade. Essa forma de análise é identificada em muitos trabalhos de cunho geográfico, quando estes são analisados nos anais de eventos científicos.

Muitos trabalhos científicos são elaborados a partir de uma perspectiva geográfica física, ou seja, da Geografia Física, na qual é possível averiguar que há um esforço em se analisar a relação sociedade e natureza de forma articulada. Essa forma de análise geográfica é bastante perceptível nos estudos referentes aos depósitos tecnogênicos, pois não há a formação desses depósitos sem a intervenção do homem no equilíbrio dinâmico dos processos naturais.

Assim, pretende-se com este texto apresentar uma possibilidade de leitura geográfica e geomorfológica dos depósitos tecnogênicos que considera uma escala de tempo histórico e é orientada por um método de interpretação da realidade conhecido como materialismo histórico e dialético. Assim, a interpretação foi realizada a partir da investigação das formações tecnogênicas identificadas no bairro Jardim Humberto Salvador, localizado na cidade de Presidente Prudente-SP. 


\section{A importância da categoria tempo e sua relação com a escala de análise dos depósitos tecnogênicos}

Os depósitos tecnogênicos podem ser definidos como formas ou depósitos que são "resultantes da atividade humana, abrangendo depósitos construídos como os aterros, ou depósitos induzidos, oriundos de sedimentos que se depositam em virtude da erosão decorrente do uso do solo” (Suertegaray et al. 2008, p. 236).

Essas formas advêm de um conjunto de processos originados a partir das atividades humanas, tendo sido incorporadas aos estudos geográficos por apresentar uma gênese e morfologia diretamente ligadas às formas de apropriação e ocupação do relevo.

Estas formas, ou estes depósitos, apresentam características específicas, que demonstram que sua gênese diferencia-se dos processos ditos puramente naturais, como a erosão geológica. A formação ocorre quando há a intervenção do ser humano na dinâmica dos processos naturais, provocando a quebra no equilíbrio dinâmico.

Isso pode resultar em uma aceleração das erosões, gerando processos geomorfológicos que passam, dessa forma, a desprender mais sedimentos e carrear materiais de origem antrópico-técnica, transportandoos e depositando-os em compartimentos geomorfológicos com menor declividade, sendo estes as planícies aluviais e/ou baixas vertentes.

Assim, os depósitos tecnogênicos passam a constituir a paisagem geográfica, sendo organizados a partir de várias composições de camadas que se diferenciam de acordo com a constituição dos materiais e sedimentos encontrados em cada estrato.

Como estas formas se manifestam principalmente no ambiente urbano (pois este concentra uma determinada quantidade de pessoas, e é onde o processo de urbanização é mais acentuado), a escala de análise privilegiada é a do local em detrimento do regional e do global, e o tempo considerado é o tempo histórico, ou o tempo que faz, utilizado por Suertegaray \& Nunes (2001).

$\mathrm{O}$ texto A natureza da Geografia Física na Geografia, escrito por Suertegaray \& Nunes (2001), faz uma reflexão a respeito da questão do tempo e da escala de análise de diferentes processos, que são ligados aos estudos geomorfológicos. Assim, os autores mostram que atualmente muitos trabalhos da Geografia Física estão privilegiando os estudos mais pontuais, principalmente aqueles voltados à compreensão, análise e identificação de diferentes processos que ocorrem em áreas urbanas, pois as dinâmicas naturais são alteradas e aceleradas pela intervenção antrópica. Os estudos dos depósitos tecnogênicos encaixam-se perfeitamente nesta análise.

Os autores chamam a atenção para um momento histórico atual, no qual a sociedade está cada vez mais acelerando a criação de novos equipamentos tecnológicos, capazes de romper o equilíbrio dinâmico dos processos naturais e transformar cada vez mais as características naturais do ambiente. Isso é oriundo de uma lógica de valorização dos recursos naturais, que de acordo com Casseti (1991) são tratados como mercadorias, sendo atribuído valor de troca e não apenas de uso, provocando assim profundas transformações na paisagem natural, devido à lógica de produção capitalista.

Deste modo, o presente momento é marcado pela forma como a sociedade consome os recursos naturais e produz o espaço, deixando registrada na paisagem uma série de formas oriundas de seu processo de ocupação, ou seja, os depósitos tecnogênicos, compostos por artefatos técnicos.

Perante essa capacidade do ser humano de intervir nos processos naturais, de uma maneira capaz de provocar a aceleração e a transformação da paisagem, é que vários pesquisadores começaram a rever alguns conceitos utilizados até então, para estudar e analisar as formas resultantes da apropriação e ocupação do relevo.

Neste sentido, a questão do tempo, principalmente o tempo que faz, ${ }^{1}$ é levada ao centro das discussões geográficas, e, associados a esta noção de tempo, os estudos dos fenômenos locais acabam permitindo uma série de reflexões sobre a transformação da paisagem e a aceleração dos processos naturais, como aponta Suertegaray \& Nunes (2001).

Essa perspectiva permite trabalhar com um novo período geológico, conhecido como Quinário ou Tecnógeno (Peloggia 1998), pois este cria possibilidades de debater os depósitos tecnogênicos e os impactos ambientais provocados pela ação humana.

Assim, entra em cena o conceito de Quinário, considerado por alguns pesquisadores como um novo período geológico, caracterizado pela influência do ser humano nos diversos aspectos da natureza, inclusive nas coberturas pedológicas e do relevo (Silva 2012, Peloggia 1998, Oliveira et al. 2005). Vários autores brasileiros utilizam esta perspectiva de tempo, como Peloggia (1995, 1998, 2005), Oliveira et. al. (2005), Suertegaray \& Nunes (2001), Silva (2012), Silva \& Nunes (2009), Pedro \& Nunes (2009).

Um dos primeiros autores a utilizar o termo Quinário e Tecnógeno foi Ter-Stepanian, dizendo que o Holoceno (iniciado há 10.000 anos) seria a transição do Quaternário para o Quinário ou Tecnógeno, cuja noção de tempo é baseada no tempo histórico, no tempo do ser humano.

No Quinário, a ação do ser humano influencia as novas coberturas pedológicas, assim como as formações geológicas e geomorfológicas. As atividades humanas ocorrem na litosfera de maneira desigual e contraditória, pois cada lugar apresenta características específicas devido ao modo de vida, a tecnologia empregada, o perfil socioeconômico, a cultura e os costumes.

\footnotetext{
${ }^{1}$ Também entendido como "tempo histórico", no qual se considera o ser humano, por meio de sua ação, como um importante transformador da paisagem e acelerador dos processos naturais, cujo resultado pode ser expresso pelos depósitos e os relevos tecnogênicos.
} 
A capacidade de alterar as formações rochosas, de provocar ruptura e decompor estruturas litológicas, de retirar por completo horizontes inteiros do solo e esculturar o relevo por meio de terraplanagem, faz do ser humano um agente transformador da paisagem, capaz de modelar o relevo.

Segundo Peloggia (1995), o homem vem desempenhando um papel essencial no momento atual, pois sua capacidade de modificar a natureza é cada vez mais expressiva:

“[...]o homem é um agente especificamente geológico na medida em que as consequências de suas atividades (sua ação sobre a natureza, ação ativa e mediatizada pelo trabalho) são comparáveis qualitativamente e quantitativamente significativas em relação a processos naturais e, ainda mais, quando os efeitos produzidos materializam-se em marcos estratigráficos” (Peloggia 1995, p.108).

A ação do ser humano é capaz de alterar a paisagem em um curto espaço de tempo, ou seja, em um tempo histórico ou tempo que faz, que é "o tempo das irregularidades, dos episódios catastróficos, dos eventos esporádicos, dos ritmos e das variabilidades (Suertegaray \& Nunes 2001, p.19)”.

Sob este ponto de vista, é possível compreender as transformações da paisagem oriundas da intervenção do ser humano que ocorrem na escala do local, em um curto espaço de tempo. Seria diferente se adotássemos a concepção de "tempo que escoa", ou tempo geológico, ou "tempo profundo", cuja análise principal é pautada em uma "leitura da formação da Terra baseada no tempo que passa", cujos processos de transformação da paisagem levam milhões e até bilhões de anos para ocorrer (Suertegaray \& Nunes 2001, p.19).

Uma interpretação apoiada na concepção de tempo geológico encontra sérias dificuldades em compreender o significado do tempo histórico, ou tempo que faz, incluindo a dinâmica antropogênica, já que o tempo histórico para muitos geólogos "é compreendido como um período curto, impossibilitado de provocar transformações na litosfera quando se trabalha com uma escala de tempo geológica”, ou seja, de tempo profundo (Suertegaray \& Nunes 2001, p.19). No entanto, é possível averiguar que o ser humano, por meio do desenvolvimento técnico, é capaz de alterar a paisagem em pouco tempo, como, por exemplo, quando rodovias são construídas em meio às serras, ou quando colinas são construídas a partir da deposição de resíduos sólidos, como os grandes aterros sanitários.

Diante dessa concepção de tempo histórico, é possível averiguar que a ação humana na superfície terrestre tem provocado transformações significativas na paisagem de diferentes lugares, pois o que antes era considerado como primeira natureza atualmente apresenta as marcas características da sociedade, tornando-se uma segunda natureza.

Nesta perspectiva, o momento presente tem levado muitos pesquisadores, como os geógrafos, a privilegiar em seus estudos os processos e impactos que ocorrem na escala do local, em detrimento da escala regional e global. Isso se deve ao fato de que os problemas socioambientais são mais expressivos, visíveis e crônicos em locais pontuais. No entanto, esses problemas não deixam de possuir relação com outras escalas regionais e/ou globais.

Estes estudos com ênfase na escala local têm sido observados em lugares onde há maior concentração de pessoas, como dito anteriormente, e onde o capital intensifica sua atuação na busca da obtenção de maior lucratividade. Esses locais citados são as cidades, que podem ser consideradas como ambientes onde o consumo exacerbado e a depredação do ambiente natural são bastante expressivos.

Nas cidades são observados diferentes tipos de impactos ambientais, como, por exemplo, solapamento das margens dos cursos d'água, processos erosivos em vertentes, desmatamento de mata ciliar, queimadas clandestinas, contaminação do solo e das águas por meio de lançamento de esgoto, disposição irregular de resíduos sólidos e os depósitos tecnogênicos.

A maioria dos estudos dos depósitos tecnogênicos é realizada na escala local, devido à sua formação ser influenciada por intervenções muito pontuais, como a implantação de um loteamento em áreas de topos, áreas de média e alta vertente. Neste exemplo, quando um loteamento é implantado em um compartimento geomorfológico de topo e vertente, parte do material utilizado para a terraplanagem, para a implantação das ruas e para a edificação das residências acaba sendo transportado e depositado em compartimentos geomorfológicos conhecidos como planícies aluviais, fundos de vale e baixas vertentes.

Esses materiais acabam formando camadas compostas por sedimentos, artefatos técnicos, resíduos sólidos (lixo), entre outros. E essas camadas acabam registrando as fases históricas de implantação do loteamento e construção do bairro.

Em síntese, a concepção de tempo histórico permite aos pesquisadores identificar a gênese de evolução dos depósitos tecnogênicos, além de conhecer, através dos registros impregnados nas camadas, as fases históricas de transformação da paisagem local. Na escala de tempo profundo, ou tempo que escoa, seria impossível trabalhar os depósitos tecnogênicos, já que as transformações ocorrem de forma pontual e em um curto espaço de tempo (100 anos, no máximo), devido à ação do ser humano em transformar, induzir e construir novas estruturas e formas.

\section{Possíveis métodos de interpretação utilizados para analisar os depósitos tecnogênicos}

As diferentes formas de analisar, compreender e definir a dinâmica da natureza e as inter-relações com a dinâmica da sociedade partem do princípio de quais paradigmas e métodos de interpretação da realidade influenciaram e influenciam a construção do pensamento geográfico.

Nunes (2008, p.1-2) diz que a "predominância de um ou outro método de interpretação como hegemônico, 
está associada ao momento histórico em que as sociedades estruturam suas bases econômicas, políticas, culturais e ambientais”. Para cada período de evolução do pensamento geográfico, um método de interpretação da realidade se impõe em detrimento de outros, e hoje é possível verificar que alguns métodos são empregados de forma conjunta para explicar determinados processos e objetos de investigação.

De modo geral, é possível dizer que os principais métodos que influenciam a interpretação e compreensão do objeto de pesquisa podem ser três: o hipotético-dedutivo, o fenomenológico-hermenêutico e o dialético.

Conforme Sposito (2004), cada um desses métodos citados pode permitir a interpretação de processos, de relações que se estabelecem na constituição do espaço geográfico, que pode possuir um caráter mais fenomenológico, dedutivo ou dialético ${ }^{2}$ Para demonstrar isso, apresentamos a seguir uma breve explanação desses métodos, pensados para análise dos depósitos tecnogênicos.

O método hipotético-dedutivo baseia-se na interpretação pautada na descrição da paisagem ou de um processo, envolvendo hipóteses e deduções.

Este método "constrói uma teoria que formula hipóteses a partir das quais os resultados obtidos podem ser deduzidos, e com base nas quais se podem fazer previsões que, por sua vez, podem ser confirmadas ou refutadas” (Japiassu \& Marcondes 1990, p.143).

Conforme Sposito (2004, p.34), o "objeto prevalece sobre o sujeito, ou seja, o objeto estudado é posicionado a montante, influenciando o pesquisador e os seus conhecimentos, mesmo que a neutralidade científica seja um pressuposto básico. O real é descrito por meio de hipóteses e deduções”.

A descrição e dedução são bastante empregadas na análise do objeto, que pode ser uma paisagem, um processo ou um fenômeno. Nos estudos dos depósitos tecnogênicos a descrição ainda é muito utilizada para caracterizar as camadas depositadas na paisagem e os materiais constituintes. A partir dessa descrição são realizadas deduções e hipóteses para a formação daqueles depósitos, na busca de compreender o processo e os agentes responsáveis por sua origem.

O método hermenêutico- fenomenológico envolve uma interpretação dos processos por meio da sobreposição do sujeito ao objeto. Assim, são realizadas descrições do objeto a partir do ponto de vista do sujeito.

Segundo Lencioni (1999), este método é uma forma de pensar o objeto a partir da percepção do sujeito. Nele, a "consideração da percepção advinda das experiências vividas é, assim, considerada etapa metodológica importante e fundamental”, tendendo portanto a uma visão antropocêntrica do mundo e a

\footnotetext{
${ }^{2}$ Isso não quer dizer que pesquisadores não podem utilizar mais de um método de interpretação, pois em alguns momentos da pesquisa, dependendo do objeto e o objetivo, pode-se utilizar dois ou até os três métodos apresentados por Sposito (2004).
}

uma recuperação do humanismo. O espaço vivido é tratado como revelador das práticas sociais, que passam a ser referência central, pois o lugar é o centro das análises.

Assim, Sposito (2004) enfoca que o sujeito é quem descreve o objeto e suas relações, levando em consideração o seu ponto de vista. Neste sentido, o objeto torna-se elemento inferior, sendo analisado sob o ponto de vista do sujeito que o vivenciou.

Os depósitos tecnogênicos passam a ser analisados por um método fenomenológico, no qual avalia-se a relação sujeito-objeto a partir da percepção dos agentes que geraram ou induziram a formação desses depósitos. Isso pode ser aplicado à análise de um bairro já constituído e à relação que a população ocupante tem com o entorno. Muitas vezes é possível observar que os depósitos tecnogênicos se formam em áreas periféricas, onde se encontram área de pastagem, resquícios de mata e cursos d'água bastante degradados. É nestes locais que os depósitos se formam, nos quais existe uma grande quantidade de resíduos sólidos depositados em pontos inadequados, no qual é possível encontrar o lançamento de esgoto clandestino, como também solos naturais cujos horizontes $\mathrm{O}$, A ou Ap foram retirados para serem utilizados em aterros, entre outros impactos.

Por fim, o último método a ser apresentado é o dialético. Neste, os processos e as dinâmicas são analisados a partir das relações contraditórias, de forma a demonstrar uma crítica ao se analisar o objeto.

Segundo Japiassu \& Marcondes (1990, p.167), “o método dialético é aquele que procede pela refutação das opiniões do senso comum, levando-as à contradição, para chegar então à verdade, fruto da razão". Neste método é possível compreender as contrariedades que ocorrem ao se constituir o espaço geográfico.

A relação sujeito e objeto neste método acontece constantemente, de forma a se transformar; ou seja, há um contínuo movimento que gera mudanças provocadas pelas contradições oriundas do antagonismo das classes no processo de produção social, tendo as antíteses (contradições ou negação) e as teses (identidade) em constante contradição e movimento (Sposito 2004). Geralmente, trabalhos que se utilizam desse "método se caracterizam por serem mais críticos da realidade, por sua concretude e pelo fato de mostrarem as contradições existentes no objeto pesquisado” (Sposito 2004, p.46-7).

Neste método, as "relações contraditórias não precisam ser soberanas e as construções e as transformações sujeito/objeto são recíprocas” (Nunes et al. 2006, p.1).

Para Nunes (2008), analisar o objeto de estudo a partir do pensamento dialético do materialismo histórico permite tratar a relação sujeito (sociedade) e objeto (natureza) de modo dialético, pois “está na base do processo de desenvolvimento e transformação das sociedades humanas, tendo o trabalho como intermediário desta relação” (Nunes 2008, p.1-2). Isso pode ser explicado pela relação sociedade e natureza, 
pois a "dinâmica da natureza e sua organização sofrem modificações, em um grau e ritmo nunca antes observado, numa sincronia perversa, resultantes do acirramento das relações sociais de produção do modo capitalista” (Nunes et al. 2006, p.1).

Nesta perspectiva, os depósitos tecnogênicos podem ser estudados a partir da compreensão das relações de produção do espaço urbano, e as contradições empregadas que se manifestam na paisagem. Pois nesta relação, os agentes de produção do espaço urbano ${ }^{3}$ são responsáveis em apropriar, ocupar o relevo (áreas de topo, de vertentes ou de fundos de vale) e atribuir um valor de troca, além do valor de uso, quando um loteamento é implantado.

Deste modo, determinados compartimentos geomorfológicos podem ser desvalorizados no mercado imobiliário devido à lógica adotada pelos agentes de produção do espaço urbano. Por exemplo, há loteamentos implantados em áreas desvalorizadas, com características específicas, tais como vertentes com declividades acentuadas (superiores a 30\% de declive), fundos de vale degradados, antigos depósitos de lixo e ausência de infraestrutura básica. Essas características podem contribuir na desvalorização dessas áreas, que muitas vezes são ocupadas por grupos sociais de baixa renda.

Por outro lado, há exemplos de áreas vinculadas a compartimentos geomorfológicos que eram desvalorizadas (no mercado imobiliário) e que passaram por uma valorização devido aos interesses dos agentes de produção do espaço urbano. Por exemplo, fundos de vale degradados ${ }^{4}$ que foram apropriados e ocupados pelos agentes de produção do espaço urbano e que receberam infraestrutura ${ }^{5}$ revertendo o cenário de degradação, passando a ser urbanizados e consequentemente valorizados.

Existem bairros implantados em compartimentos geomorfológicos que possuem lotes desvalorizados e é fácil encontrar resíduos sólidos e/ou líquidos despejados ou depositados em locais inapropriados. Ao longo do tempo, e com os períodos de chuva, esses resíduos vão sendo transportados e assentados em compartimentos geomorfológicos com baixa declividade, como em áreas de planícies aluviais ou baixa vertente. Ao mesmo tempo em que se defende um discurso de preservação do ambiente natural, é possível verificar que os próprios agentes de produção do espaço contribuem para a degradação do ambiente, tornando o discurso contraditório com as práticas analisadas.

Este modo de pensar tem influenciado na procura de uma articulação entre as diversas áreas da Geografia. O "materialismo histórico e dialético, que pressupõe não

\footnotetext{
3 Proprietários dos meios de produção, sobretudo os grandes industriais; proprietários fundiários; promotores imobiliários, o Estado e os grupos sociais (Corrêa 1989).

${ }^{4}$ Que apresentam poluição, assoreamento, lixo, ausência de mata ciliar, entre outros.

5 Como exemplo, iluminação, rede de drenagem urbana, canalização do córrego, retirada do lixo do esgoto que antes era despejado no curso d’água.
}

haver separação entre a história da natureza e a história dos homens [impõe] um elo entre os processos de apropriação e de transformação executados pelo ser humano, cuja compreensão da natureza enquanto matéria reelaborada pelo trabalho humano tem no conceito de natureza um dos pontos fundamentais" (Bernardes \& Ferreira 2003 apud Nunes et al. 2006, p.6). É nesta perspectiva que as análises dos depósitos passam de uma mera descrição das camadas tecnogênicas para a compreensão das relações contraditórias que se estabelecem entre as dinâmicas da sociedade e da natureza na geração dos referidos depósitos tecnogênicos.

\section{A formação de depósitos tecnogênicos em ambientes urbanos}

Os depósitos tecnogênicos são depósitos ou formas resultantes da ação do homem ao desenvolver atividades que mantêm seu modo de vida. Esses depósitos são constituídos dos mais variados tipos de materiais. Isso envolve desde restos de materiais de construções, resíduos sólidos, resquícios de queimada, além dos materiais minerais que compõem os grupos de solos naturais, como argila, areia e silte.

A formação dos depósitos tecnogênicos pode ser resultante de vários processos relacionados à apropriação e ocupação do relevo. No entanto, será apresentada a seguir a gênese de formação de depósitos tecnogênicos identificados em um bairro periférico, localizado na cidade de Presidente Prudente/SP, conhecido como Jardim Humberto Salvador (figura 1), para que possam ser analisados os diferentes tipos de depósitos encontrados no bairro, a partir de uma leitura geográfica com ênfase geomorfológica, utilizando-se como método de interpretação da realidade o materialismo histórico, a partir de uma escala de tempo histórico.

O Jardim Humberto Salvador (figura 2) é um bairro que possui um histórico de apropriação e ocupação do relevo bastante interessante. Este loteamento foi implantado em 1995, por meio de políticas públicas que promoviam o desfavelamento de determinadas áreas da cidade, ocorrido na década de 1990 na gestão do prefeito Paulo Constantino. Atualmente, o bairro possui mais de 3.100 habitantes. 

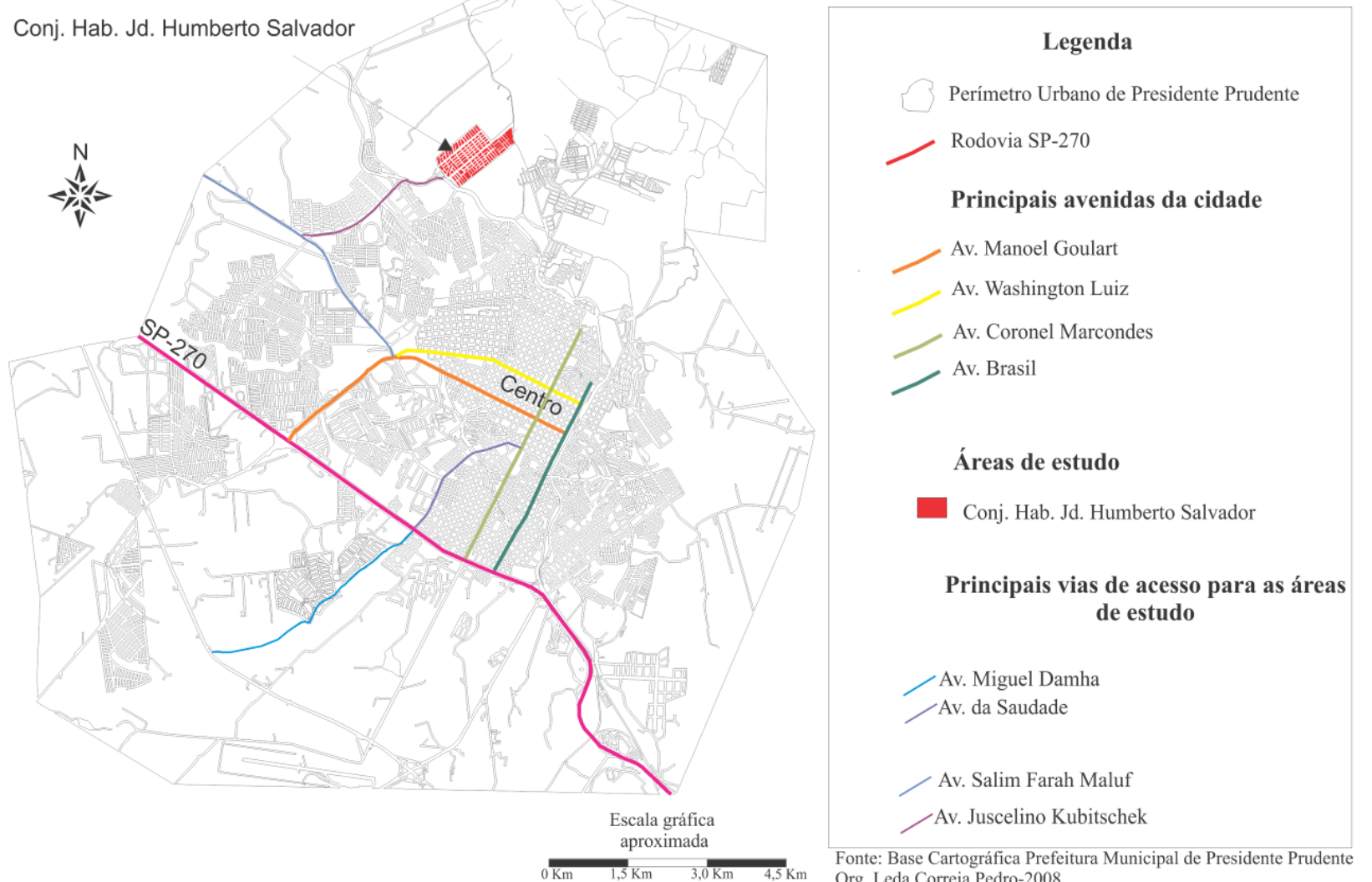

Figura 1: Localização do Jardim Humberto Salvador na malha urbana de Presidente Prudente/SP Fonte: Pedro (2008)

O projeto de desfavelamento realizado no município removeu famílias que viviam em áreas de favelas para grandes glebas ainda não loteadas, como o Conjunto Habitacional Jardim Humberto Salvador (zona norte) e o Parque José Rotta (localizado na zona leste).

As áreas favelizadas estavam distribuídas por toda a cidade, e a maior concentração se dava na zona leste da cidade de Presidente Prudente (onde se concentram as áreas de exclusão social e as vertentes com declividades acentuadas).

Os moradores que viviam em áreas de favela foram cadastrados para um sorteio que contemplaria parte da população que enfrentava problemas de moradia.

No entanto, para que as famílias pudessem se cadastrar deveriam atender alguns critérios: a) receber até quatro salários mínimos; b) morar em Presidente Prudente há três anos; c) não possuir imóvel; d) ter uma família constituída; e) ser eleitor do município.

Logo após a confirmação de contemplação dos lotes, as famílias receberam a autorização para lavratura de escritura de doação, com encargos para a construção e o projeto de edificação de $46,80 \mathrm{~m}^{2}$, com área média dos lotes de $135 \mathrm{~m}^{2}$, largura de $9 \mathrm{~m}$ e fundo de $15 \mathrm{~m}$.

No total, foram 2.022 lotes. No entanto, segundo Jesus (2005), foram cedidos mais 29 lotes no Conjunto Habitacional Jardim Humberto Salvador, totalizando
2.051 lotes. Estes lotes foram implantados em uma área pública. Por esse motivo os proprietários possuíam "o direito de uso”, mas não o de propriedade do terreno.

Segundo o contrato, as famílias deveriam construir e ocupar o imóvel em dois anos. Estas famílias teriam que seguir o projeto de edificação cedido pela prefeitura ou um projeto particular, com os encargos para a construção no lote, não podendo alienar o lote em um período de dez anos.

O Conjunto Habitacional Jardim Humberto Salvador foi implantado descontinuo à malha urbana, dificultando o acesso da população não apenas ao centro da cidade, como a outros lugares. Também não possuía infraestrutura, tais como asfalto, creches, postos de saúde, ausência parcial de iluminação pública em alguns pontos do bairro, muros de arrimo, sistema de captação de águas pluviais etc.

No caso do Conjunto Habitacional Jardim Humberto Salvador, verifica-se a participação de diferentes agentes de produção do espaço urbano, tais como a Prefeitura Municipal de Presidente Prudente (ação pública) e a Associação de Moradores do bairro, cada qual com seus papéis e interesses. 


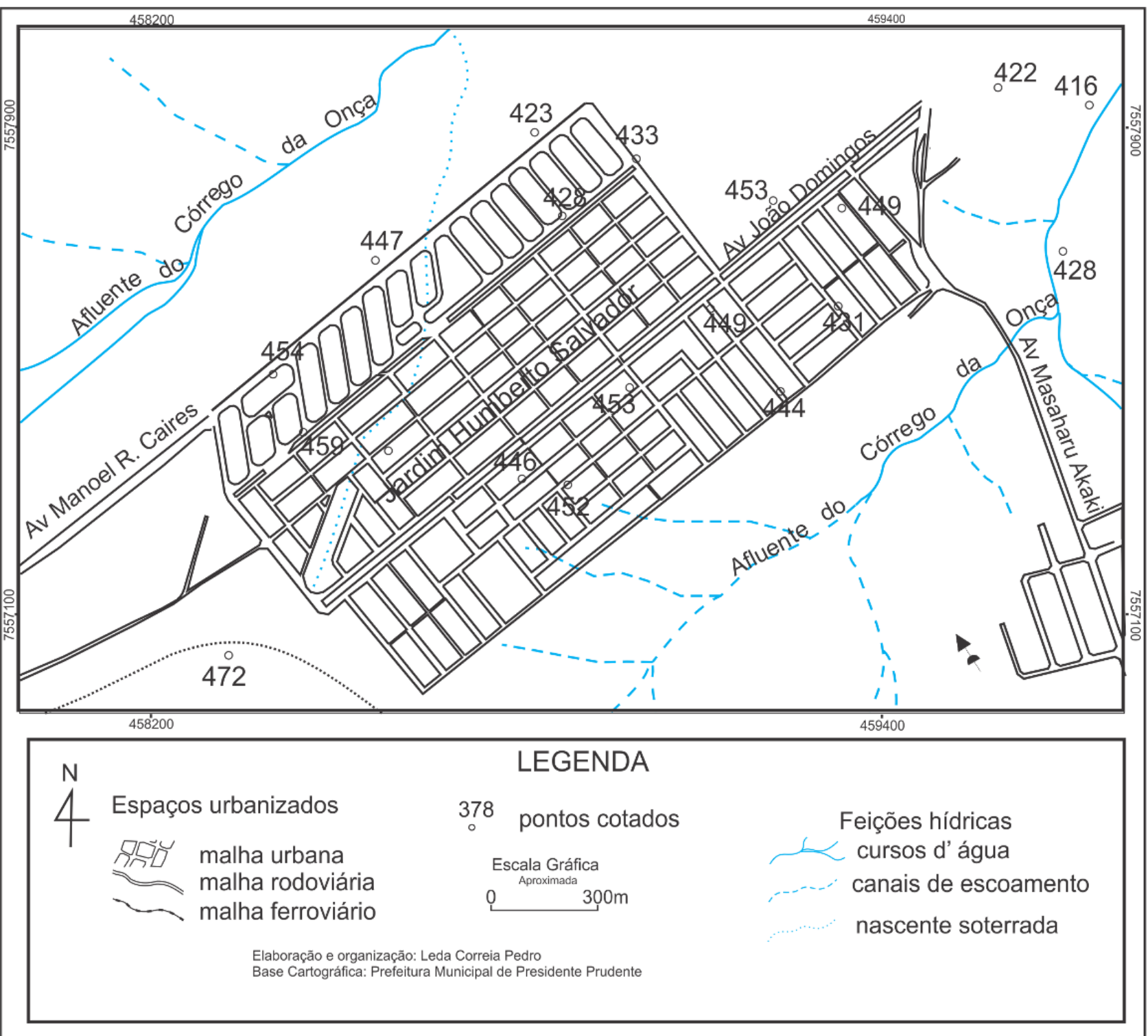

Figura 2: Localização do Jardim Humberto Salvador na malha urbana de Presidente Prudente/SP. Fonte: Pedro (2008)

A prefeitura, buscando resolver o problema de habitação, desenvolveu uma política habitacional de distribuição de lotes. Mas simplesmente doar lotes não foi o suficiente para sanar este quadro.

De acordo com Jesus (2005), quando o loteamento foi implantado não havia infraestrutura e serviços básicos para atender a população de baixa renda. Muitos moradores acabaram vendendo estes lotes por diversos motivos, sendo um deles a falta de infraestrutura e a distância em relação ao centro (Pedro 2008).

A área escolhida para a implantação deste loteamento reflete a lógica seguida pelos agentes de produção do espaço urbano, já que a área encontrava-se descontínua à malha urbana (figura 3), estratégia adotada para valorização de determinados vazios urbanos, fazendo parte de um eixo de áreas de exclusão social, onde se encontravam os terrenos com baixo valor de venda, devido às características físicas (declividade acentuada) e sociais (área de exclusão social) deste local.

O bairro Jardim Humberto Salvador foi construído no setor norte da cidade de Presidente Prudente, sobre um relevo de colinas amplas com topos convexizados (Nunes et al. 2006), que se encontra compartimentado em três domínios morfológicos: domínio dos topos, domínio das vertentes e domínio dos fundos de vale (figura 3).

O relevo onde se encontra o Jardim Humberto Salvador é composto pelo domínio dos topos suavemente ondulados, com predomínio de interflúvios estreitos, não apresentado características físicas adequadas à expansão urbana. 




Figura 3: Carta geomorfológica do Jardim Humberto Salvador e áreas adjacentes

Apresenta várias cabeceiras de drenagem em anfiteatro associadas às nascentes que abastecem os afluentes do córrego da Onça. Já em relação às vertentes, estas apresentam morfologias côncavas, convexas e retilíneas, cujas funções são diferenciadas, por exemplo, as vertentes côncavas, que são predominantes nesta porção do relevo, têm função de concentrar águas pluviais, diferentemente das convexas que dispersam as águas. Os fundos de vales apresentam morfologias em berços e $\mathrm{V}$, sendo o primeiro mais amplo e associado às planícies aluviais, e o segundo mais encaixado (fechado).

Em se tratando das declividades (figura 4), pode-se observar a predominância das classes $10 \%$ a $15 \%$ de declive, sendo os pontos mais íngremes áreas onde se encontram os declives de $20 \%$ a superiores a $30 \%$. 


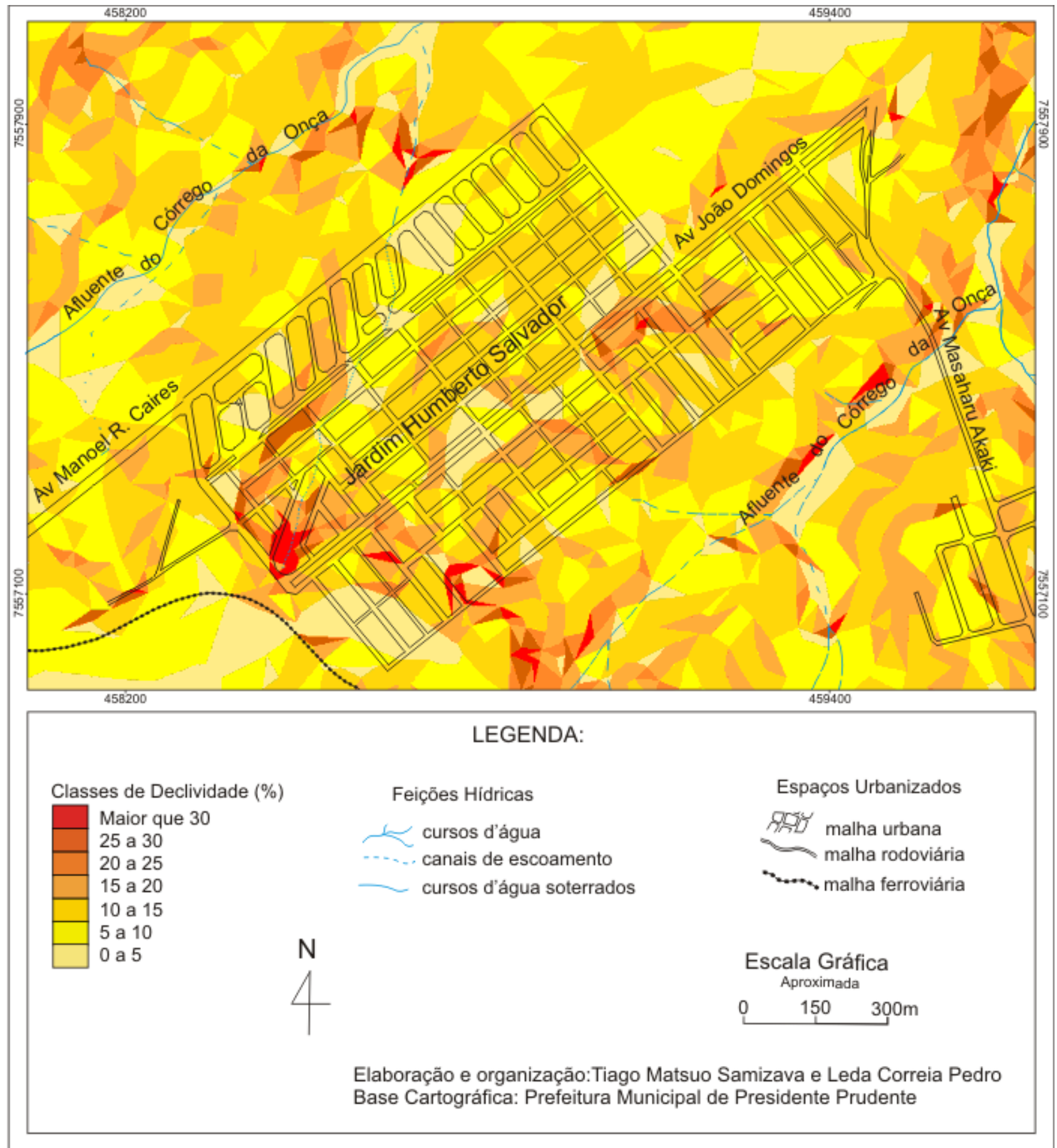

Figura 4: Carta Clinográfica com ênfase no Jardim Humberto Salvador

Em relação às altitudes identificadas no bairro analisado, é possível verificar que os intervalos que apresentam pontos cotados com altitudes mais elevadas superam a marca dos $445 \mathrm{~m}$, podendo atingir $470 \mathrm{~m}$ (figura 5) em pontos mais elevados. Já os pontos cotados com altitudes menos elevadas variam entre 415 e $440 \mathrm{~m}$. 


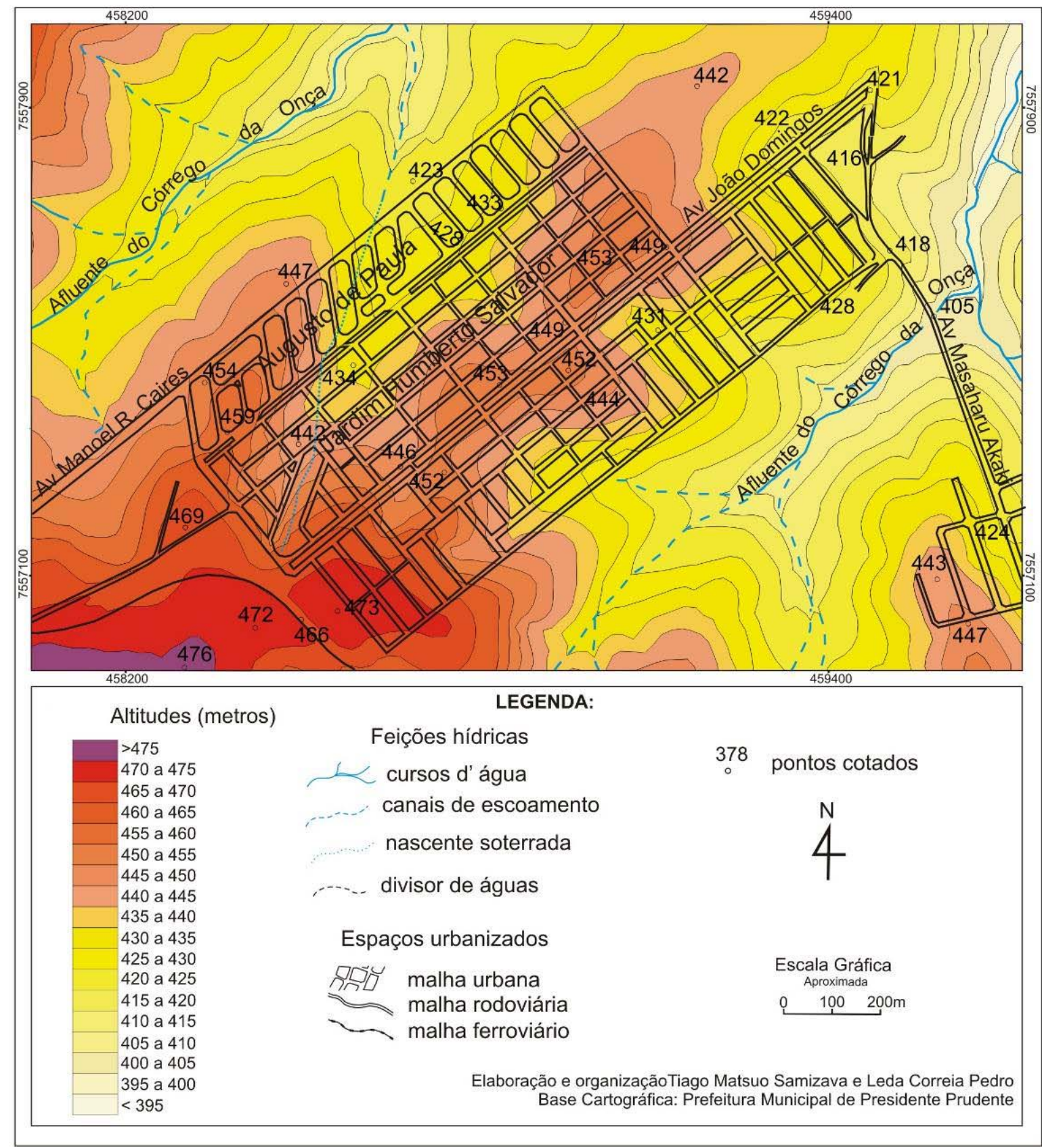

Figura 5: Carta Hipsométrica com ênfase no Jardim Humberto Salvador

O histórico de apropriação e ocupação do bairro, além de apontar os problemas enfrentados pela população ocupante e a política de erradicação de áreas de favela aplicada na cidade de Presidente Prudente, também demonstra que o loteamento não poderia ser implantado no local em que se encontra atualmente, devido às características físicas.

Para analisar as transformações decorrentes da ação do ser humano no relevo e a formação de depósitos tecnogênicos, foram estudados alguns pontos específicos no bairro Jardim Humberto Salvador (figura 6), que demonstram como a ocupação pode interferir no equilíbrio dinâmico dos processos naturais, além de provocar a aceleração e a geração de impactos ambientais urbanos.

Além desses compartimentos geomorfológicos, o loteamento foi implantado em uma área onde há várias cabeceiras de drenagem em anfiteatro, e nascentes que promoviam o abastecimento dos afluentes do córrego da Onça (zona norte da cidade).

Essas cabeceiras de drenagem em anfiteatro foram totalmente desfiguradas por meio da terraplanagem e da construção de aterros (foto 1). A prática é realizada em vertentes que apresentam declividades acentuadas, nas quais se faz o nivelamento por meio de aterros, corte de talude e retirada de solo, formando assim uma espécie de “degrau”, sendo que esses lotes devem 
apresentar terrenos totalmente planos, na maioria dos

casos.

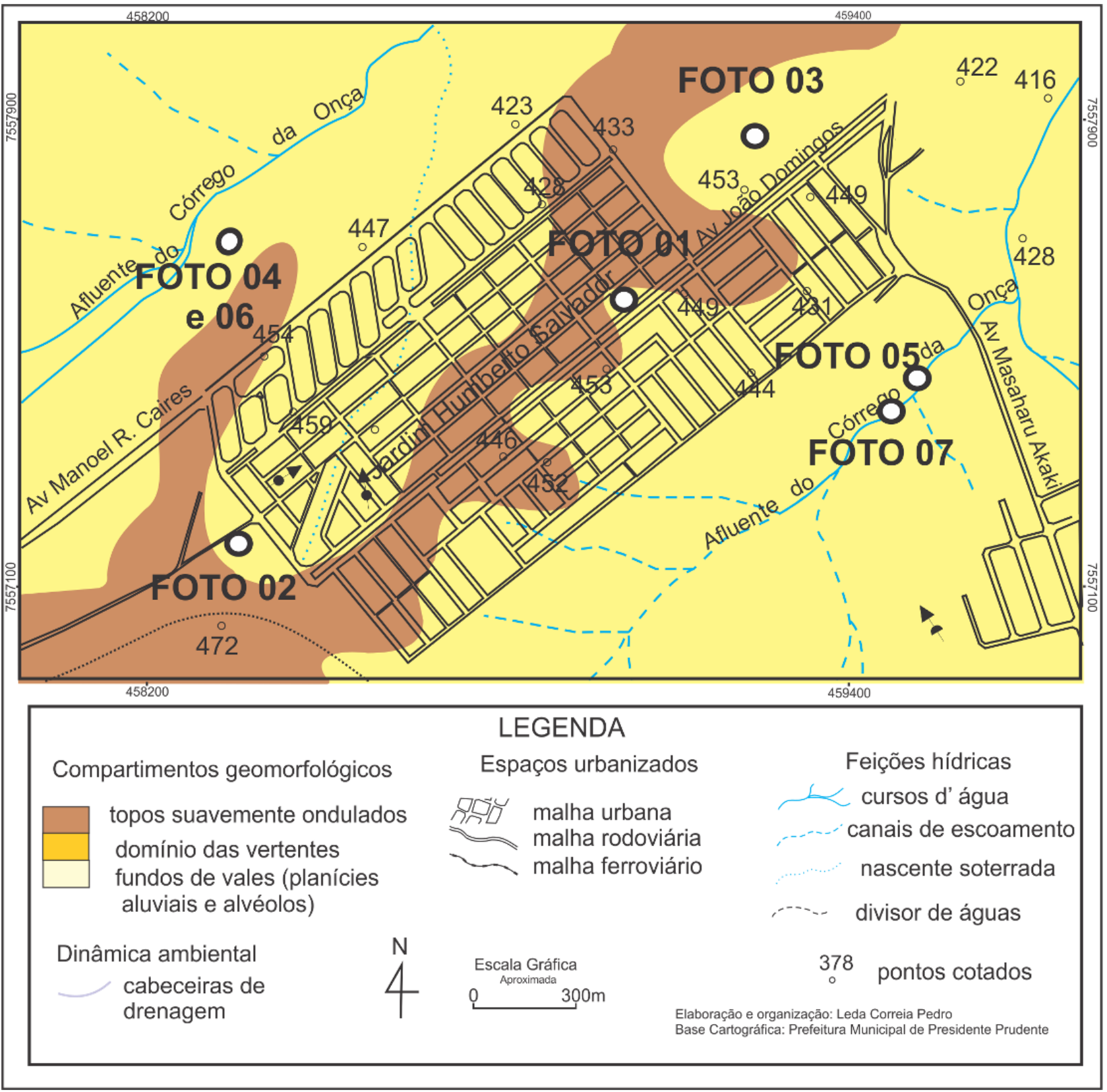

Figura 6: Localização dos pontos estudados e registro das fotos

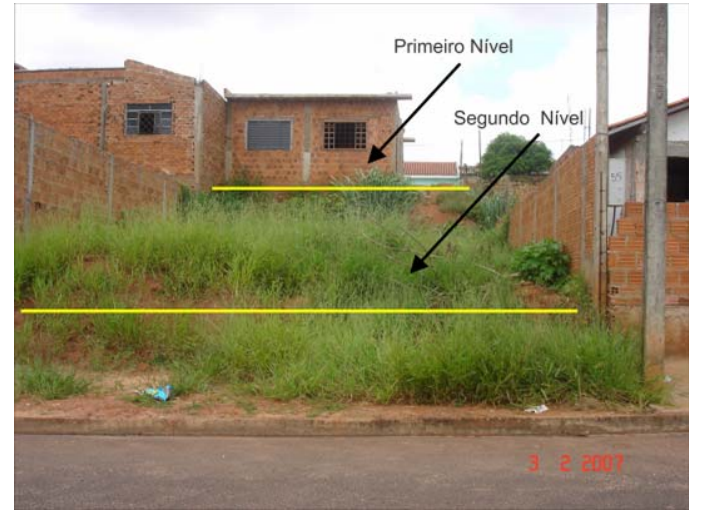

Foto 1: Vertentes com declividades acentuadas, ocupadas para fins de implantação de loteamento, esculturadas pela ação do ser humano, por meio da terraplanagem, cortes de taludes e aterros. O primeiro nível mostra um lote cuja vertente sofreu processo de terraplanagem e aterro. No segundo nível encontra-se um lote que será esculturado por processo de terraplanagem e retirada de solo para ser edificado com a construção de residências.

Essa forma de intervenção na paisagem provoca a decapitação de horizontes de solos naturais que foram retirados de seu local de origem, sendo depositados sobre outros horizontes, formando os aterros.

As nascentes vinculadas às cabeceiras de drenagem (foto 2) foram soterradas, drenadas e escondidas no início da implantação do loteamento, para que os lotes não apresentassem áreas úmidas.

Toda essa área deveria estar protegida, ou seja, ser uma Área de Preservação Permanente (APP), devido à existência de várias nascentes e cursos d’água que 
abastecem os afluentes do rio do Peixe, principal rio que abastece a cidade de Presidente Prudente.

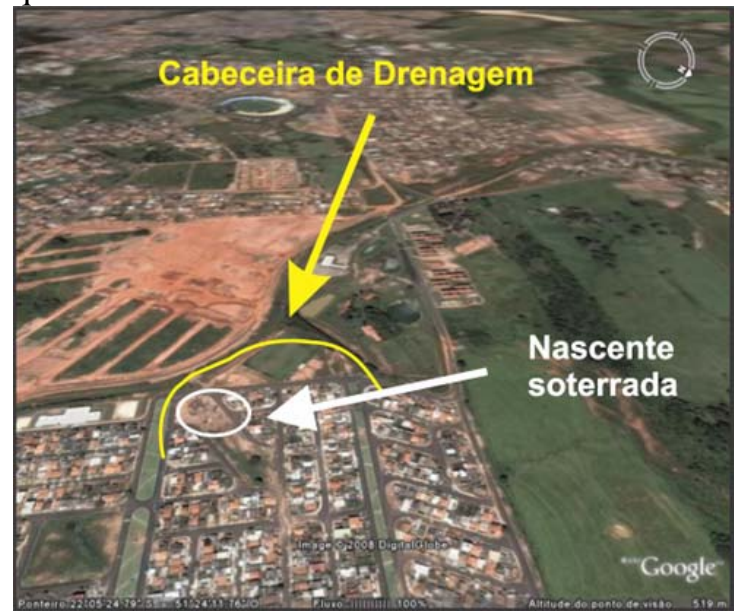

Foto 2: Cabeceira de drenagem em anfiteatro esculturada pela ação humana, com nascente que foi soterrada para a implantação do loteamento

No início da implantação do bairro, muitos lotes e arruamentos encontravam-se sem nenhuma cobertura, seja ela vegetal ou por manta asfáltica, o que desencadeou uma série de formas erosivas, como os sulcos, as ravinas e as voçorocas.

Com a distribuição de todos os lotes, iniciou-se a segunda fase, que envolve a constituição do bairro, ou seja, a edificação das casas.

A partir do processo de aterramento e terraplanagem que desfigurou áreas de topos, de vertentes e de nascentes (cabeceiras de drenagem), e com as primeiras chuvas de verão, o material oriundo desse processo foi carreado para as áreas mais baixas do relevo (foto 3), ou seja, as planícies aluviais formando diferentes camadas que representam fases de deposição induzidas pela ação antrópica.

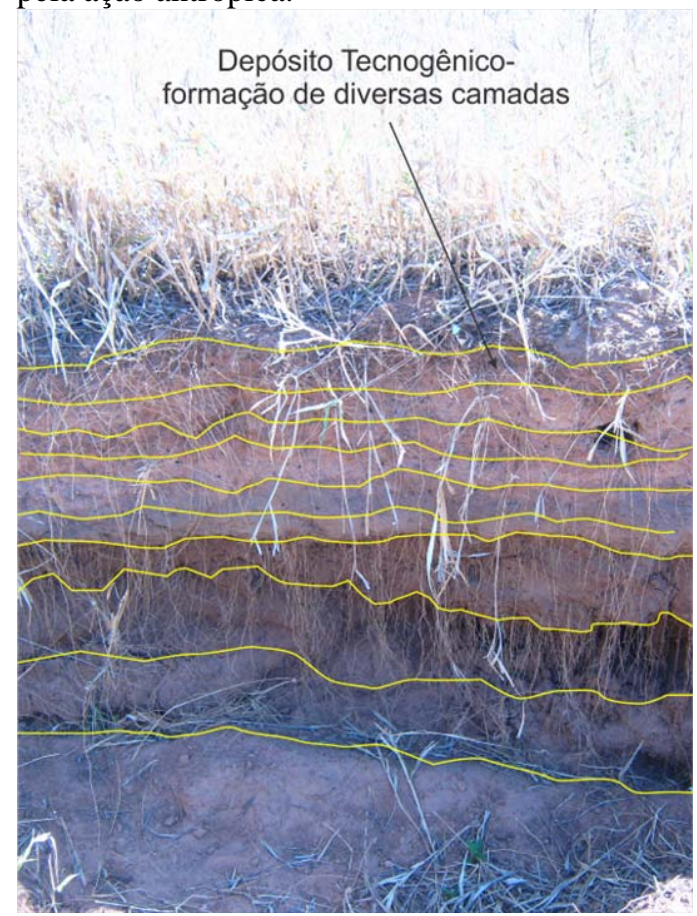

Foto 3: Camadas de deposição de sedimentos e artefatos humanos induzidos pela ação antrópica
O resultado desse processo pode ser observado na paisagem, na forma de um registro da intervenção do ser humano naquele momento histórico.

A próxima etapa de implantação do bairro ocorreu a partir da edificação das residências, ou seja, da construção das casas. Naquele momento, as casas foram sendo construídas, e o material rejeitado (sobras do material de construção) foi depositado em áreas periféricas do bairro, ou no terreno vizinho.

Novamente, quando ocorrem as chuvas, por meio do escoamento superficial, esses restos de material de construção são transportados e depositados em áreas de fundo de vale ou de planícies aluviais, formando uma outra camada, onde podem ser encontrados sedimentos misturados a restos de material de construção.

Também foi possível verificar que os depósitos tecnogênicos deram origem a novas formas de relevo, como, por exemplo, as planícies tecnogênicas (foto 4).

Outra etapa que envolve a ocupação de um bairro refere-se ao término das casas e à ocupação pelos donos da residência. Com as pessoas vivendo em suas casas, outro tipo de artefato tecnogênico começa a aparecer nas camadas dos depósitos tecnogênicos, ou seja, os resíduos sólidos. Na foto 5 é possível observar que nas camadas do depósito tecnogênico é possível identificar resíduos sólidos, como uma garrafa pet e um pedaço de mangueira.

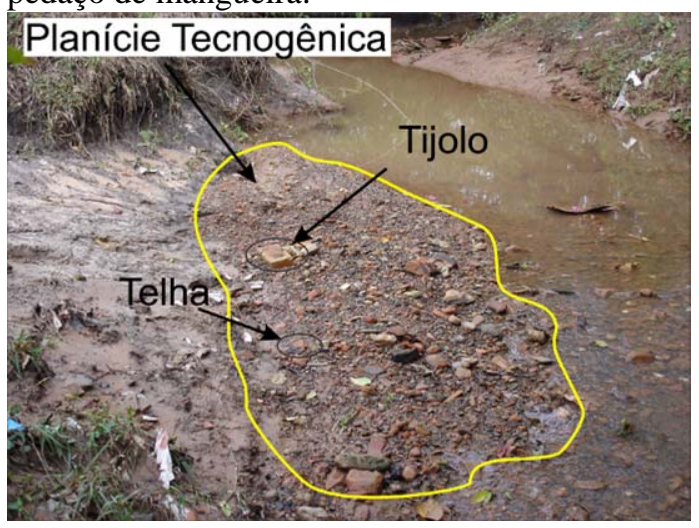

Foto 4: Planície Tecnogênica formada a partir da deposição de material de construção e sedimentos oriundos das áreas a montante

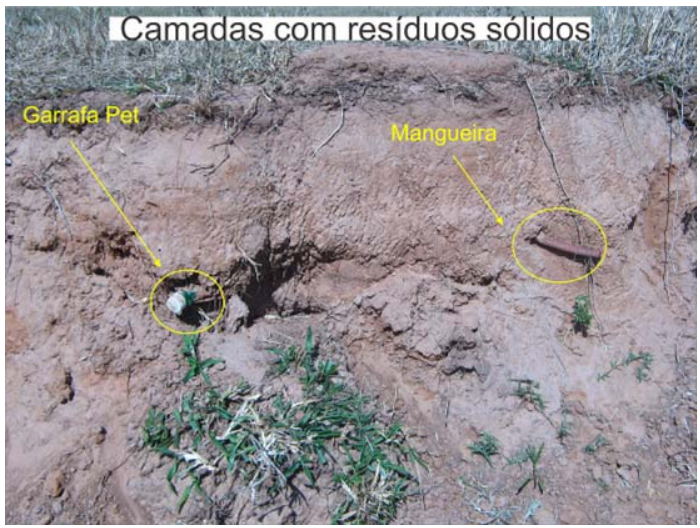

Foto 5: Depósito tecnogênico composto por diferentes artefatos humanos

Esses artefatos representam uma fase do histórico de ocupação do relevo, que ao longo do tempo deixa registrada na paisagem as intervenções indiretas do ser 
humano ao ocupar determinado compartimento geomorfológico.

Além desses tipos de registro, foi encontrado em outro local um depósito tecnogênico com uma espessa camada de resíduos sólidos (foto 6), que permitiu interpretar mais um episódio do histórico de ocupação desse relevo.

Esse local foi descoberto após forte chuva, ocorrida nos meses de janeiro a março de 2008, quando a enxurrada, advinda das áreas a montante totalmente impermeabilizadas, foi direcionada ao fundo de vale. A força da enxurrada transportou parte das camadas tecnogênicas superiores, deixando aflorar camadas inferiores repleta de resíduos sólidos.

Esse depósito tecnogênico é uma antiga área de lixão que foi desativada há muito tempo. O depósito não foi formado a partir da ocupação do relevo onde atualmente encontra-se o bairro Jardim Humberto Salvador, apresentando dessa forma outra gênese de formação, pois foi uma área escolhida para depositar todos os resíduos coletados na cidade de Presidente Prudente.

Com a população morando no bairro, é possível observar vários tipos de resíduos sólidos sendo depositados em locais inadequados. Isso se agrava no decorrer do tempo, já que esse material é transportado para as áreas de fundo de vale, formando uma nova camada tecnogênica, registrando mais uma fase referente ao histórico de apropriação e ocupação do loteamento e à constituição do bairro.

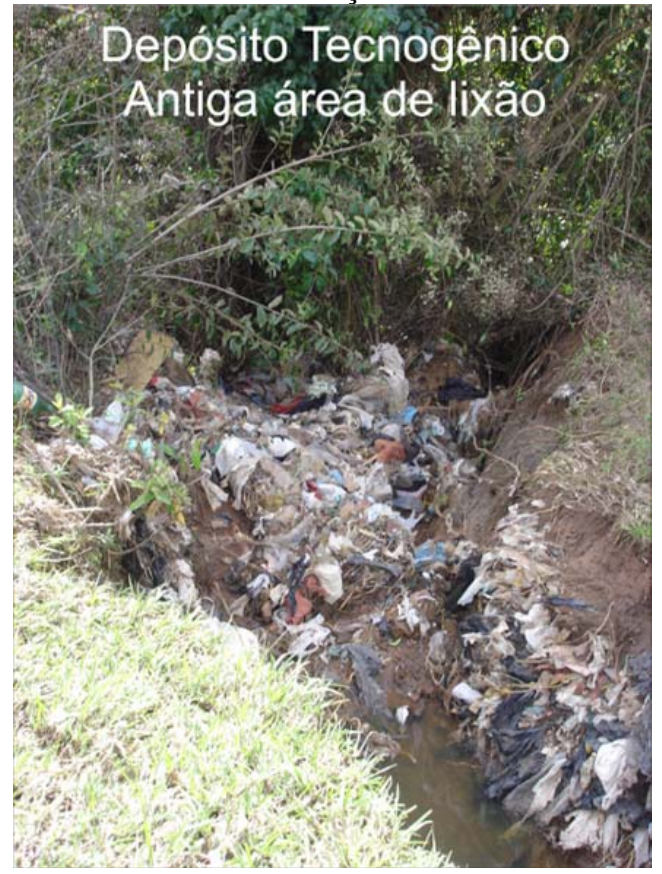

Foto 6: Antiga área de lixão localizado nas áreas adjacentes ao bairro Jardim Humberto Salvador

Essas fases que envolvem a implantação de um loteamento e a constituição de um bairro deixam registros na paisagem que revelam um histórico de apropriação e ocupação deste relevo, por meio dos estudos dos depósitos tecnogênicos.

\section{Conclusões}

A análise do processo de formação dos depósitos tecnogênicos em ambientes urbanos permitiu realizar uma nova leitura geográfico-geomorfológica de alguns dos principais efeitos e respostas do ambiente, decorrentes do processo de apropriação e ocupação do relevo em áreas urbanas, além de demonstrar como esta dinâmica transforma a paisagem.

A ação do homem vem alterando a dinâmica natural dos processos físicos, contribuindo para a intensificação da erosão, do escoamento concentrado e deposição de materiais oriundos da ocupação do relevo.

Com isso, pode-se afirmar que, em linhas gerais, as alterações ambientais observadas na área de estudo correspondem a modificações significativas na morfologia original e na dinâmica dos processos geomorfológicos, de forma a intensificar suas potencialidades naturais, gerando novas morfologias, cujas camadas representam um tempo histórico referente às fases de apropriação e ocupação do relevo. Esses fatos, associados aos ambientes de ocupação inadequada, promovem o surgimento de áreas com elevado comprometimento da qualidade ambiental.

Assim, este texto cumpre a função específica de introduzir um debate acerca da degradação ambiental e estimular estudos de casos concretos referentes à apropriação e ocupação do relevo e à geração de depósitos tecnogênicos a partir de uma leitura geográfico-geomorfológica, cujo método balizador de interpretação da realidade é o materialismo histórico e dialético, sob uma perspectiva de tempo histórico.

\section{Referências}

Casseti V. 1991. Ambiente e Apropriação do Relevo. São Paulo: Contexto, $147 \mathrm{p}$.

Corrêa R.L. 1989. O espaço urbano. São Paulo: Editora Ática, 94 p.

Japiassu H., Marcondes D. 2005. Dicionário básico de Filosofia. Rio de Janeiro: Jorge Zahar, 1990, 2012 p.

Jesus P.M. 2005. "Produção do espaço urbano no Jardim Humberto Salvador, Presidente Prudente /SP. Afastamento, Exclusão ou Segregação socioespacial?”. Monografia (Bacharelado em Geografia).Faculdade de Ciências e Tecnologia, Universidade Estadual Paulista, Presidente Prudente.153 p.

Lencione S. 1999. Região e Geografia. São Paulo: Edusp, 224 p.

Nunes J.O.R. 2008. Perspectivas da Geografia Física: A natureza na Geografia produzida no Brasil. In: I Colóquio Brasileiro de História do Pensamento Geográfico. Uberlândia. I Colóquio Brasileiro de História do Pensamento Geográfico. [s.p.]

Nunes J.O.R., Sant'Anna Neto J.L., Tommaselli J.T.G., Amorim M.C.C.T., Perusi M.C. 2006. A influência dos métodos científicos na Geografia Física. Terra Livre, 2:119:130.

Oliveira A.M.S., Brannstrom C., Nolasco M.C., Peloggia A.U.G., Peixoto M.N.O., Coltrinari L. 2005. Tecnógeno: registro da ação geológica do homem. In: Souza C.R.G.. Suguio K., Oliveira A.M.S., Oliveira P.E. (ed.) Quaternário do Brasil. Ribeirão Preto: Holos, 363:376 p.

Pedro L.C. 2008. Ambiente e apropriação dos compartimentos geomorfológicos do conjunto habitacional Jardim Humberto Salvador e condomínio fechado Damha - Presidente Prudente/SP. Dissertação (Dissertação de Mestrado). Faculdade de Ciências e Tecnologia, Universidade Estadual Paulista, Presidente Prudente, 153 p..

Pedro L.C., Nunes J.O.R. 2009. As ações antrópicas e as formações tecnogênicas: o caso do Jardim Humberto Salvador em Presidente Prudente/SP. Revista Geografar (UFPR), 4:120:142. 
Peloggia A.U.G. 1995. A dialética da Geologia (temas de Geologia inspirados na obra de Friedrich Engels, e suas aplicações). Revista Brasileira de Geociências. São Paulo, 25(2):107:110. Disponivel em: http://sbgeo.org.br/pub_sbg/rbg/vol25_down/ 2502/2502107.pdf. Acesso em 22 de setembro de 2013.

Peloggia A.U.G. 1998. O Homem e o Ambiente Geológico: Geologia, Sociedade e Ocupação Urbana no Município de São Paulo. São Paulo: Xamã, 271 p.

Peloggia A.U.G. 2005. A cidade, as vertentes e as várzeas: a transformação do relevo pela ação do homem no município de São Paulo. Revista do Departamento de Geografia (USP), São Paulo, 16:24-31.

Silva É.C.N., Nunes J.O.R. 2009. Análise dos depósitos tecnogênicos e suas relações com os processos geomorfológicos na cidade de Presidente Prudente. In: XXI Congresso de Iniciação Científica da Unesp, 2009, São José do Rio Preto. XXI Congresso de Iniciação Científica da Unesp, [s.p.].

Silva É.C.N. 2012. Formação de depósitos tecnogênicos e relações com o uso e ocupação do solo no perímetro urbano de Presidente Prudente SP. Dissertação (Dissertação de Mestrado).. Faculdade de Ciências e Tecnologia, Universidade Estadual Paulista, Presidente Prudente, 183p.

Sposito E.S. 2004. Geografia e Filosofia: contribuição para o ensino do pensamento geográfico. São Paulo: Editora Unesp, 199 p.

Suertegaray D.M.A., Nunes J.O.R. 2001. A natureza da Geografia Física na Geografia. Revista Terra Livre, n. 17, $2^{\circ}$ semestre, São Paulo, 11:23 p. Disponível em: http://www.agb.org.br/files/TL_N17.pdf Acessado em 11 de setembro 2013.

Suertegaray D.M.A., Rossato M.S., Bellanca E.T., Fachinello A., Cândido L.A., Silva C.R. 2008. Terra Feições Ilustradas. Suertegaray D. M. A. (Org.) $3^{\circ}$ ed., Porto Alegre: Editora da UFRGS,263 p.

${ }^{\mathrm{i}}$ Recebido 20 de outubro de 2013 Aceito 01 de agosto de 2014 